Backwards ran his sentences, and some of his ideas were equally opaque. In support of punk eek, for example, he wrote that "species are individuals ... by all vernacular criteria", which is at best obscure, and at worst obscurantist.

As Reflections portrays, its hero showed an increasing regard for style over content, and was resistant to the notion that anyone should dare to edit his writings. The pinnacle - the very summit, crown and peak - of his great Olympus of orotundity was his last voluminous volume, The Structure of Evolutionary Theory, published in the year of his death. All the authors agree that this is not a book to be lightly tossed aside, but their motives for saying so vary. Its reviews are quoted with a certain relish: "an elephantine opus"; "pathological logorrhea"; "billowing clouds of verbal flatulence" - but Gould had no doubt of its value. In it he came out with the idea of life as a series of interlocking hierarchies and of a grand unification of its sciences into some post-Darwinian consilience, comprehensible only to the chosen.

Poe was much the same. His last substantial work, Eureka: A Prose Poem, published just before his own demise, discusses the relationship of man to God, and to "the Material and Spiritual Universe: of its Essence, its Origin, its Creation, its Present Condition and its Destiny". It was seen by Poe as replacing
Newton's ideas about gravity. Poe wrote that "What I have propounded will (in good time) revolutionize the world of Physical and Metaphysical science". Some see in it a presage of the Big Bang and of modern astronomy, but others ridicule its pretensions, its rambling nature and its overblown prose. Nine decades later, Albert Einstein described Eureka as a "beautiful achievement of an unusually independent mind". Perhaps, one day, the same will be said of Gould.

Steve Jones is professor of genetics at University College London, London WC1E 6BT, UK. His most recent book is Coral: A Pessimist in Paradise. e-mail: j.s.jones@ucl.ac.uk

\title{
Does genius breed success?
}

\section{Outliers: The Story of Success \\ by Malcolm Gladwell \\ Allen Lane/Little, Brown: 2008. \\ 256 pp/320 pp. $€ 16.99 / \$ 27.99$}

Thomas Edison's insight more than a century ago that genius is 1\% inspiration and $99 \%$ perspiration is often quoted, yet few seem to believe it. The common notion of genius is that we are either born with it or we're not. This seductive idea enables us to hold up successful people as exotic, propelled to triumph by talent alone. More than that, it reinforces the impression that those who are masters of one field are masters of many. Hence the widely held assumption, recently disproved, that financiers who have been successful in one market are expert in all; or that the 76 Nobel science laureates who endorsed Barack Obama's electoral campaign were worth listening to in matters of politics.

Malcolm Gladwell aims in his book Outliers to dismantle the idea of innate genius once and for all. His main point is that it is nonsense to explain someone's success solely in terms of their own actions and choices. Culture, family environment, opportunities and, above all, hard work count far more than any inherited quality. "It's not enough to ask what successful people are like," he says. "It is only by asking where they are from that we can unravel the logic behind who succeeds and who doesn't."

Gladwell follows the formula that worked for him in his previous bestsellers The Tipping Point and Blink, weaving psychological and sociological theory into a compelling narrative. He asserts that few stars of any field succeed without putting in at least 10,000 hours of practice, including 'prodigies' such as Mozart.
Similarly, few make it to the top without being handed a life-changing opportunity early in life, generally one they neither deserved nor earned. Both Bill Joy, founder of Sun Microsystems, and Bill Gates, creator of Microsoft, for example, learned to program computers as a result of attending a university or private school with unrivalled equipment. Gladwell argues those early opportunities enabled Joy and Gates to improve beyond their peers and take advantage of opportunities down the line. They were talented, but they were also fortunate.

Gladwell is convincing almost too convincing. Psychological and sociological theories of behaviour are never tidy, and the reader may sense that they are being manipulated by clever selection of data. Presumably, Gates and Joy had classmates who spent similar amounts of time in front of computers but never became billionaires. Gladwell claims that the key to The Beatles' success was the time they spent in Hamburg in early 1960s Germany, where they performed 270 five-hour gigs in 18 months. Clearly this improved their technical proficiency, but surely what set The Beatles apart was their songwriting, another skill entirely. Many other musicians put in long playing hours but don't become famous. The question is not so much whether Gladwell's thesis rings true - it does - but whether it is as comprehensive as he makes out, which is unlikely.

The book suffers another flaw, one of structure rather than argument. After 158 pages on the 'ecology' of genius, Gladwell shifts his focus to the effect of culture on people's behaviour. $\mathrm{He}$ includes a chapter on how flight crews from cultures that emphasize hierarchy and deference, such as South Korea and Colombia, are more likely to crash their planes because co-pilots and flight engineers are less inclined to challenge the captain when they think he is making an error. Although this discussion is interesting and broadly about success, it seems to fall some way from where the story began.

Outliers is probably Gladwell's most important book yet. Unlike his previous two, it has implications for public life. His demonstration that intelligence, above a certain threshold level, has no bearing on future success should turn university selection policy on its head. To win a Nobel prize, you need to be smart enough to get into a decent university, nothing more. His most graphic example of how intelligence above a certain level is irrelevant to achievement is an experiment by psychologist Lewis Terman. Terman failed in his attempt to nurture the future elite of the United States by selecting people for their very high IQ; although many of his 'geniuses' did well, very few went on to become nationally recognized.

Gladwell also asks why Asian students tend to be so much better at maths than their western counterparts. He reckons it is firstly because the regularity of the Asian number system means that basic tasks such as addition can be done more easily, and secondly that Asia's ricegrowing culture, involving hours of dedication in the fields, has imbued its people with a dogged attitude essential for tackling mathematical problems. Although that might sound far-fetched, his suggestion that underachieving children in the West could transform their performances if they studied during the holidays makes sense. That's what Gladwell does best: he gives you a new way of seeing the world, and it's worth taking him seriously for that. Michael Bond is a science writer based in London. e-mail: michael.bond@btinternet.com 